\title{
INDUSTRY-UNIVERSITY COOPERATIVE RESEARCH CENTERS
}

\author{
James D. Adams \\ Eric P. Chiang \\ Katara Starkey \\ Working Paper 7843 \\ http://www.nber.org/papers/w7843 \\ NATIONAL BUREAU OF ECONOMIC RESEARCH \\ 1050 Massachusetts Avenue \\ Cambridge, MA 02138 \\ August 2000
}

This research was supported by NSF grant SBR-9502968. We thank Eleanora Voelkel and Richard Anderson for administering the Survey of Industrial Laboratory Technologies 1996 and Don Siegel and Paula Stephan for helpful comments. Denis Gray (North Carolina State University) and Bill Neufeld (NSF) provided information concerning the NSF Science and Technology Centers and Engineering Research Centers discussed in this paper. This paper was given at a conference on "Organizational Aspects of University-Industry Technology Transfer," held at Purdue University in June 2000. The views expressed herein are those of the authors' and not necessarily those of the National Bureau of Economic Research.

(C) 2000 by James D. Adams, Eric P. Chiang and Katara Starkey. All rights reserved. Short sections of text, not to exceed two paragraphs, may be quoted without explicit permission provided that full credit, including (C) notice, is given to the source. 
Industry-University Cooperative Research Centers

James D. Adams, Eric P. Chiang, and Katara Starkey

NBER Working Paper No. 7843

August 2000

JEL No. O31, O33, O38

\begin{abstract}
This paper takes a first look at the effect of Industry-University Cooperative Research Centers (IUCRCs) on industrial R\&D laboratories. IUCRCs are small academic centers designed to foster technology transfer between universities and firms. Since IUCRCs depend on industry support we expect them to further the research of member companies.

Our findings suggest that IUCRCs promote industry-university technology transfer. We find strong associations between laboratory membership in IUCRCs and the importance of faculty consultants, co-authorship with faculty and hiring of graduate students to the laboratories. IUCRC membership contributes small increments, not always statistically significant, of $2 \%$ in laboratory patenting and research expenditures. Both estimates are larger for National Science Foundation IUCRCs, consistent with their quality and their sorting to larger laboratories.

These results survive a simultaneous equation analysis of the joint decision to patent and join IUCRCs. Nevertheless more work is needed to separate the effect of the IUCRCs from the matching mechanism that assigns IUCRCs to R\&D laboratories.
\end{abstract}

James D. Adams

Department of Economics

University of Florida

224 Matherly Hall

Gainesville, FL 32611-7140

and NBER

adams@dale.cba.ufl.edu

Katara Starkey

Department of Economics

University of Florida

Gainesville, FL 32611-7140
Eric P. Chiang Department of Economics University of Florida Gainesville, FL 32611-7140 


\section{Introduction}

This paper takes a first look at the influence of Industry-University Cooperative Research Centers (IUCRCs) on patenting and research expenditures by industrial R\&D laboratories. IUCRCs are one of a larger set of policies, most of them put in place since 1980, that are designed to foster technology transfer between universities and firms. Since IUCRCs are small academic centers that depend mostly on industry support, we expect them to advance the research of member companies. The evidence in this paper is consistent with this hypothesis.

A brief overview of recent policy sets the stage for this paper's study of IUCRCs. The Bayh-Dole Act of 1980 gave universities the right to patent inventions resulting from federally funded research. The result was a large increase in patents, and in licensing of university patents ${ }^{1}$. The Economic Recovery Tax Act of 1981 extended the R\&D tax credit to companyfinanced academic research, thereby promoting company support for universities. The Small Business Innovation Research Act of 1982 (SBIR) required agency set-asides to support startups, including some headed by university researchers. The IUCRCs also proliferated after 1980 as a result of federal and state initiatives ${ }^{2}$. The National Science Foundation (NSF) centers, which are leaders among IUCRCs in terms of quality, also date from this period ${ }^{3}$. Like BayhDole, R\&D tax credits for company-financed research at universities, and SBIR support of university researchers, the purpose of the IUCRCs is to strengthen the relationship between industry and the academy, especially the colleges of engineering, using prior investments in public science as leverage.

\footnotetext{
${ }^{1}$ See Henderson, Jaffe, and Trajtenberg (1998) and Thursby and Thursby (2000).

${ }^{2}$ Cohen, Florida, Randazzese and Walsh (1998) estimate that $60 \%$ of the IUCRCs were founded after 1980 . They attribute nearly all the increase to federal and state initiatives that have subsidized the IUCRCs at a young age.

${ }^{3}$ The first NSF Science and Technology Center was founded in 1978, while the first Engineering Research Center was founded in 1984. This information is drawn from unpublished NSF data, including Gray (various years).
} 
We now turn to the comparatively brief literature on IUCRCs. Cohen, Florida, Randazzese, and Walsh (1998) discuss changes in university research brought about by IUCRCs. The rewards from university research traditionally come from reputation. Reputation promotes mobility and mobility in turn generates salary increases and teaching reductions. Thus the rewards to academic research depend on the dissemination of findings and open science. But the rewards to industrial research derive mostly from corporate profits, and these rely on confidentiality. Hence the coming together of academic and industrial research moves academic research towards secrecy, in conflict with standard academic practice ${ }^{4}$.

Cohen and associates (1998) carried out a survey of IUCRC directors that bears on these issues. They find that research is more applied, communication of research findings more restricted, information from published papers more likely to be deleted, and publication itself more likely to be delayed, as the IUCRCs attach greater importance to improving industrial products and processes.

Despite these disadvantages, universities have eagerly sought to add more IUCRCs because of the funding that they offer. The $9.4 \%$ decline in real federal funding per researcher from 1979 to 1991 is a factor that explains this change in university policy ${ }^{5}$.

Improved linkages with academia have also been useful to firms, especially those that have downsized their R\&D establishments. Having contracted their R\&D, sometimes because of the relaxation of antitrust, firms have become more interested in joint research with academics (Mowery, 1995).

\footnotetext{
${ }^{4}$ To minimize conflict over open science Brooks and Randazzese (1998) suggest the creation of "buffer institutions" that take a middle ground between universities and business firms. These would employ distinct personnel and remove temptation, and probably those tempted, from academic departments.

${ }^{5}$ See Brooks and Randazzese (1998).
} 
Industry-university joint research has expanded in spite of any transaction costs, suggesting that the policies have had an effect ${ }^{6}$. An interesting study by Blumenthal and associates (1986) suggests that costs of transacting may be important. They find that companyfinanced university $R \& D$ in biotechnology yields a higher ratio of patents to $R \& D$ than internal R\&D. If costs of transacting are significant then joint research with universities, and indeed other partners, has to be more productive than internal research.

We have seen that the literature concentrates on the impact of IUCRCs on universities. In contrast this paper studies the influence of the IUCRCs on member firms using a sample of R\&D laboratories ${ }^{7}$. The laboratories are a critical interface between firms and IUCRCs and thus a reasonable starting point for the analysis. Although this point of view is limited because it does not deal with the effect on firms and consumers outside the IUCRCs, it provides a start in understanding IUCRCs from the perspective of member firms ${ }^{8}$.

Our evidence suggests that IUCRCs have increased knowledge spillovers between member firms and universities. The centers' dependence on member firm support seems to generate the right incentives, at least for member firms. And the willingness of firms to join IUCRCs suggests that private marginal benefits are at least equal to private marginal costs.

We find that laboratories belonging to IUCRCs are $2 \frac{1}{2}$ times larger and more scienceoriented than non-members. This is not surprising given that the fixed costs of joining the IUCRCs favor large and sophisticated laboratories. We also find that laboratory preferences for faculty consulting and joint authorship are more strongly associated with IUCRC membership

\footnotetext{
${ }^{6}$ Consistent with the change in policy, interactions between universities and firms have increased in recent years. The share of industry-supported academic research rose from 2.6\% in 1970 to $7.1 \%$ in 1997 (National Science Board (1998), Appendix table 5-2).

${ }^{7}$ Throughout this paper the term "R\&D laboratory" refers to any research group within a firm and not necessarily to a separate, formally dedicated research facility.

${ }^{8}$ IUCRCs satisfy the confidentiality requirements of firms. According to Link and Bauer (1989), Chapter 3, R\&D managers regard IUCRCs as having better appropriability and secrecy than research joint ventures.
} 
than any other channels of university influence. In regression-style analysis we examine the influence of IUCRC membership on patenting and R\&D expenditures by the laboratories. Member laboratories issue 0.5 additional patents compared with non-members, holding constant industry, time, laboratory specialization, $R \& D$ budget, and $R \& D$ in the rest of the firm. This effect is statistically significant and is stronger for the NSF IUCRCs than for all IUCRCs. Based on average member patents of 11.5 the IUCRC effect amounts to a $4 \%$ increase. However, once we control for laboratory proficiency - the number of Ph.D. researchers, the 20-year stock of the firm's patents near the laboratory, and science orientation - the effect of IUCRC membership declines to 0.3 patents or $2 \%$, and becomes insignificant at the given sample size.

The influence of IUCRC membership on R\&D is stronger than the effect on patents and survives the proficiency controls. Holding laboratory size and proficiency and other variables constant, IUCRCs increase R\&D by 0.4 million dollars. This is a $2 \%$ increase in average R\&D of 22.1 million. This effect is again greater for NSF IUCRCs. Membership of all kinds has a stronger effect on learning about university research than on total R\&D.

These estimates are subject to an important qualification. Membership in IUCRCs is a function of size and proficiency of the laboratory, just as patents are a function of the same variables. The identification problem is this: can the influence of IUCRC membership on laboratory productivity be separated from the influence of productivity on membership? Our tentative answer is yes, though more accounting is needed for the matching of IUCRCs and laboratories. We undertake a simultaneous equation analysis of patents jointly with the decision to join IUCRCs. We find that the results for patents change rather little as a result of this analysis. In the process new findings are brought to light for IUCRC membership. Besides laboratory R\&D we find that the stock of federal R\&D in universities as well as tastes for faculty 
consulting and joint authorship with faculty increase the probability of IUCRC membership.

The rest of the paper is arranged as follows. Section II describes the potential effects of IUCRCs on firms. Section III discusses the survey data that underlie the empirical work. Section IV presents the findings, while section $\mathrm{V}$ concludes and discusses extensions of the analysis.

\section{Characterization of IUCRCs}

\section{A. Types of IUCRCs}

Our data allow us to distinguish two types of IUCRCs. We know whether laboratories are members of any IUCRC and whether they are members of two varieties of NSF IUCRC, the NSF Science and Technology Centers (S\&TCs) and the NSF Engineering Research Centers (ERCs). The two differ in size, length of grant, and focus on basic research, all of which are greater for the ERCs. But our data set does not allow us to separate the S\&TCs from the ERCs, since firms either belong to both types or to neither one. Thus NSF IUCRC membership is treated as a single variable in the analysis below.

The average quality of IUCRCs almost surely varies by type. Non-NSF centers tend to be lower ranked, the NSF S\&TCs middle-ranked, and the NSF ERCs ranked highest. The reason is that the stiffness of the competition to obtain the IUCRCs varies in the same order. Many nonNSF IUCRCs are obtained through state level competitions, whereas the scarce NSF ERC grants are the hardest to win ${ }^{9}$. In terms of our two-fold division non-NSF centers are likely to be of lower quality than NSF centers. Of course, one should keep in mind that this ranking is just a tendency and that IUCRCs of the first rank cut across all types of center.

\footnotetext{
${ }^{9}$ Costs to universities of seeking to obtain IUCRCs are unknown, even though they are important for the purpose of cost-benefit analysis.
} 


\section{B. Research Agenda for the Study of IUCRCs}

In this paper we pursue three objectives. We study the channels of university influence that are associated with IUCRC membership and which describe the nature of its effect. In addition we explore the influence of the centers on laboratory patenting and R\&D. Finally we study the determinants of membership in IUCRCs.

Given that IUCRCs increase the reliance of universities on industrial funding, one would think that membership in IUCRCs is associated with increased importance to firms of university technology transfer. This reasoning suggests that the most important channels of the IUCRCs' effect are faculty consulting, joint research with industry and the hiring of graduate students, with generalized flows of university ideas of secondary importance. We expect that IUCRCs confer economic rent on faculty although we are unable to study salaries directly. It is important to point out, as have Cohen and associates (1998), that IUCRCs change the incentives of faculty and divert their interests away from campus and towards the world of enterprise.

Assume that IUCRCs have an effect on firms. At what stage of innovation does this occur? For IUCRCs engaged in research that directly supports new products or processes one might think that the IUCRCs could resolve difficult problems and stimulate innovation. But the influence of the IUCRCs could be more indirect. For example IUCRCs could lead industrial laboratories to learn more and thus conduct better research in the future. This is another way that collaboration with university centers extends the boundaries of firm R\&D.

Why do firms become members of IUCRCs? This is another area of interest. We noted the possibility that IUCRCs solve problems and stimulate projects but there are other advantages of membership such as improved liaison with faculty and hiring of top graduate students. The empirical work explores these different motives for joining IUCRCs. 


\section{Description of the Data}

Most of our data come from a survey of 600 R\&D laboratories owned by 200 publicly traded firms in the chemicals, machinery, electrical equipment, and transportation equipment industries ${ }^{10}$. Patents granted, R\&D expenditures, and value of sales data are collected for the years 1991 and 1996. All the other data pertain to the 1991-1996 period as a whole and do not vary over time. Table 1 describes the distribution of the laboratories and parent firms by industry. This distribution is almost uniform except for smaller numbers in transportation equipment, reflecting higher concentration ratios in this industry.

The survey yielded 208 observations representing 220 laboratories, for a response rate of $37 \%(220 / 600)$. There is no response bias either by industry or size of laboratory, except for a somewhat lower response among pharmaceutical laboratories ${ }^{11}$.

The survey contains indicators of membership for all IUCRCs and NSF IUCRCs ${ }^{12}$. Both are dummy variables that are equal to one if the laboratory is an IUCRC member and 0 otherwise. While it would be useful to have data over time on the identities and numbers of IUCRCs to which the laboratory belongs, we do not have this information. This is mostly because of the reporting burden that collecting this extra data would impose, given the other functions of the survey instrument.

\footnotetext{
${ }^{10}$ See Adams (2000) and Adams, Chiang and Jensen (2000) for further details on the survey of R\&D laboratories.

${ }^{11}$ Reasons given by the pharmaceuticals for not responding were two: (a) the survey was not exclusively focused on the pharmaceutical industry and (b) too many surveys had already been submitted to pharmaceutical laboratories.

${ }^{12}$ The relevant question in the survey was:
}

"Do you belong to any of the following types of university research centers? Indicate by checking yes or no.

1. University-Industry Technology Centers

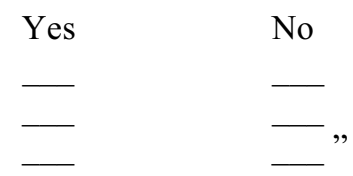


Table 2 presents descriptive statistics on $R \& D$ inputs and outputs of the $R \& D$ laboratories and reports these statistics by general IUCRC membership. The results indicate that on average IUCRC laboratories are larger and generate more output than non-member laboratories, and most of these differences are significant.

Unlike table 1, which treats laboratories as unique observations, table 2 pools the data across 1991 and 1996. Thus the 310 observations in table 2 account for 155 laboratories in table 1. Data for IUCRC and non-IUCRC laboratories are shown on the left and right of the table. R\&D inputs such as numbers of scientists and engineers, numbers of Ph.D. (or MD) scientists, and laboratory R\&D budget are $2^{1 / 2}$ times larger for IUCRC laboratories. R\&D outputs include patents granted, sometimes with missing values imputed by US Patent and Trademark Office (USPTO) patents by firm and location, and sales from new products. Output is also larger in member laboratories though in varying degrees ${ }^{13}$. The size differences between IUCRC members and non-members imply that benefits of membership increase with size. Moreover, since IUCRCs are matched with larger laboratories the effects of IUCRC membership are likely to be confounded with size of the laboratory, a problem that we address at length below.

Table 3 reports chi-square $\left(\chi^{2}\right)$ statistics from $2 \times 2$ contingency tables ${ }^{14}$. These tables describe the coincidence of membership in IUCRCs and importance to the laboratory of various channels of university influence ${ }^{15}$. Table 3 is concerned with the correlation between variables

\footnotetext{
${ }^{13}$ Patents granted are less than proportionate to R\&D budget. This is probably because larger labs have a lower propensity to patent their inventions, and concentrate on more valuable inventions.

${ }_{15}$ Tables 3 and 4 consist of unique laboratory observations and are not pooled over time.

${ }^{15}$ The relevant question in the survey (excerpted) was:
}

"Below are some firm-university interactions. Circle the number to indicate the importance of each to your lab.

Firm-University Interaction

1. Engineering Graduates

$$
\text { not applicable }
$$

1 unimportant

2 important

3

4 very important $5 "$ 
rather than causality, a standard application of contingency tables.

We define a channel of university influence as important if an R\&D laboratory assigns it a score of at least three on a five-point Likert scale (see fn. 15). The $\chi^{2}$ statistics test the null hypothesis of independence of each channel from IUCRC membership ${ }^{16}$. If the statistic is different from 0 at the one-percent level then the two variables are significantly correlated and not independent. Table 3 shows that five channels are significantly correlated with membership. These are engineering graduates, science graduates, university faculty consulting and contract research, and joint authorship with university scientists. The $\chi^{2}$ tests suggest that consulting, joint research, and hiring of graduate students are the major contributions of IUCRCs to firms. The two channels of university influence that stand out as most related to IUCRC membership are importance to laboratories of faculty consulting and joint authorship. From universities' perspective this suggests that IUCRCs are a vehicle for providing income and publications to participating faculty. But notice that table 3 does not suggest that IUCRCs promote general knowledge flows from universities to firms or the licensing of university patents.

The survey contains a second indicator of IUCRC affiliation. This consists of citations to specific university research centers, complete with addresses that consist of city and state ${ }^{17}$. Unfortunately the citations are flawed by some omissions. Not all laboratories that belonged to

In addition to engineering graduates (above) the list of university channels included science graduates, personnel movements from university to lab, university faculty consulting, contract research, flows of university research ideas to industry, joint authorship with university scientists, and licensing of university patents. These are the eight channels discussed in the text and in table 3.

${ }^{16}$ See Brownlee (1965) Chapter 5 for a discussion of contingency tables and the $\chi^{2}$ tests of independence.

17 The relevant question in the survey was:

"List as many as five of these research centers whose research was most important for the conduct of your laboratory's R\&D over the past five years.

Research Center \#

City, State, Country 
IUCRCs bothered to cite specific IUCRCs. Table 4 demonstrates. In 121 cases laboratories said they were not members of IUCRCs and consistent with this did not cite specific centers. But in 42 out of 74 cases where laboratories said they were members of IUCRCs no centers were cited. In five other cases no membership was claimed but one IUCRC was cited, primarily because respondents defined IUCRCs as research joint ventures. Thus 37 (74-32+5) laboratories, or about $20 \%$ of the sample, did cite specific IUCRCs. In the 42 cases where no specific IUCRC is cited we drop the observations from an analysis that uses these data. The evidence on specific IUCRCs is fragmentary, so we relegate it to a brief discussion in the text of section IV.

We identified 54 citations to specific IUCRCs by the 37 citing laboratories. We were able to obtain R\&D histories on 40 of these 54 citations. Thus the match rate of the IUCRC R\&D data to citations was 74\% (40/54). To achieve this we carried out a Survey of IndustryUniversity Cooperative Research Centers that polled directors of the IUCRCs cited by the industrial laboratories. The content of this survey was brief but even so we did not obtain full compliance from the IUCRC directors. We asked when the IUCRC was founded, how many full time scientists and engineers were employed in 1991 and 1996 and how large its total and company-financed R\&D budget was since 1981 or the date of founding, whichever was the more recent. Consistent with the policy discussion nearly all the matched IUCRCs are less than 15 years old. Most are small centers with R\&D budgets that are under five million dollars a year.

\section{The Influence of IUCRCs on R\&D Laboratories}

At this point we turn to a report of regression-style analysis of the determinants of laboratory patents, R\&D expenditures and membership in the IUCRCs. Tables 5 to 8 contain the results. Like table 2 the regression tables pool the data from 1991 and 1996 since patents and 
R\&D vary over time. Thus if 130 of the laboratories have non-missing data in both years then the number of pooled observations is 260 and this explains why the number of observations exceeds the maximum of 208 laboratories noted in table 1.

\section{A. Determinants of Laboratory Patents}

Table 5 explains patents issued to the laboratories as a function of IUCRC membership and other variables. The estimation method is negative binomial regression. This is a type of Poisson regression method that allows for individual differences in count data, like the patents in our sample of laboratories ${ }^{18}$.

Equations (5.1)-(5.4) contain the results for patents granted as reported in the survey. The results for hybrid patents, which impute missing values using USPTO patents for the firm and laboratory location, are shown in (5.5)-(5.8). Since (5.5)-(5.8) include imputed values, we insert a dummy variable to absorb differences due to imputation ${ }^{19}$. The specification of the patent equation is in its most complete form,

Patents $=\mathrm{f}[$ time, industry, laboratory specialization, log (R\&D budget), $\log (\mathrm{R} \& \mathrm{D}$ in the rest of the firm), $\log$ (number of Ph.D.s), $\log$ (lagged 20 year stock of the firm's patents near the laboratory), fraction of non-engineering fields important to the laboratory].

All the equations contain time and industry dummies. Two additional dummies measure specialization of the laboratory. Routine testing equals one if the laboratory is primarily engaged in testing, and zero otherwise. Joint housing with manufacturing equals one if the laboratory is located in a manufacturing plant, and thus more likely to be engaged in development rather than applied research. These controls are suppressed for brevity's sake.

\footnotetext{
${ }^{18}$ Count data are integer-valued with many zeroes and thus are non-normally distributed. See Hausman, Hall and Griliches (1984) for a discussion of count data methods applied to panel data.

${ }^{19}$ Recall that hybrid patents are patents granted, supplemented by imputed patents for firm and laboratory locations from the USPTO in cases where patents are missing. For details of the data construction see Adams (2000).
} 
The patent equations include logarithms of laboratory $R \& D$ and $R \& D$ in the rest of the firm. Laboratory $R \& D$ captures size of the $R \& D$ program. $R \& D$ in the rest of the firm, which is taken from Compustat, measures firm size and knowledge transfers from other parts of the firm. As expected laboratory and firm R\&D have positive and significant effects on patents granted ${ }^{20}$. Equations (5.1) and (5.3) report results for two specifications of IUCRC membership. In (5.1) we enter membership in all IUCRCs. We find positive and significant effects that imply an

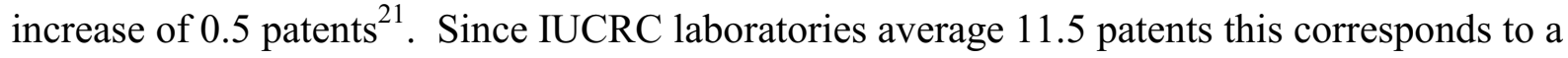
$4 \%$ increase $^{22}$. Equation (5.3) breaks up membership into NSF IUCRC and Non-NSF IUCRC dummies. NSF membership is more important and implies an increase in patents of 1.0. This is an increase of 5\% since NSF IUCRC laboratories receive an average of 19.5 patents.

In an effort to separate laboratory proficiency from IUCRC membership (5.2) and (5.4) introduce three laboratory characteristics into (5.1) and (5.3). The logarithm of numbers of Ph.D. (or MD) researchers measures size and importance of applied science in the laboratory. The logarithm of the stock of the firm's patents over the previous 20 years near the lab captures the laboratory's long run propensity to patent ${ }^{23}$. Finally the fraction of non-engineering fields in academic fields that are important to the laboratory could reflect distance from commercialization and thus reduce the number of patents. The three variables improve the fit of

\footnotetext{
${ }^{20}$ The regression coefficient for laboratory R\&D measures the elasticity of patents (see Adams and associates (2000)) and is significantly less than one. Possible reasons include left-out importance of inventions, emphasis of larger laboratories on major innovations, and a lower propensity to patent in top laboratories for reasons of secrecy. Diminishing returns to $\mathrm{R} \& \mathrm{D}$ are an implausible explanation for the elasticity being less than one.

${ }^{21}$ To see this use the formula $e^{\delta_{j}}-1$, where $\delta_{j}$ is the regression coefficient on the IUCRC membership dummy. The formula expresses the change in patents due to IUCRCs. See Adams and associates (2000).

${ }^{22}$ Members of IUCRCs have R\&D budgets of 16.2 million \$ (of ' 87 ) and 11.5 patents granted so that the patent to R\&D ratio is 0.71 per million $\$$. Non-members have R\&D budgets of 8.4 million $\$$ (of ' 87 ) and 6.4 patents. Thus the patent to R\&D ratio is 0.74 . Members of NSF IUCRCs have R\&D budgets of 23.7 million $\$$ and 19.5 patents, yielding a patent to R\&D ratio of 0.82 . Non-NSF IUCRC members have R\&D budgets of 8.3 million $\$$ and 4.4 patents and a patent to R\&D ratio of 0.53 . Either NSF centers confer real benefits or they work with elite laboratories that have a high patent to $\mathrm{R} \& \mathrm{D}$ ratio.
} 
the equation. The likelihood ratio test statistic that compares (5.1) and (5.2) is $\chi^{2}(3)=27.6$ and is significant at the 0.001 level $^{24}$. The number of $\mathrm{Ph} . \mathrm{D} . \mathrm{s}$ and the stock of firm patents near the laboratory are positive and often significant but the share of non-engineering academic fields is negative and significant, suggesting that distance from commercialization does increase with this variable.

The effect of IUCRC membership decreases in (5.2) and (5.4) compared with (5.1) and (5.3). The implied increase in patents is 0.3 in (5.2) or $2 \%$ of the 11.5 patents granted to member laboratories. The implied increase due to NSF IUCRC membership is 0.7 in (5.4). Point estimates (5.2) and (5.4) are 60\% of (5.1) and (5.3) and no longer significant given the sample size.

Equations (5.5)-(5.8) replace patents granted with hybrid patents. Recall that hybrid patents replace missing values of patents granted with USPTO patents for the firm and locality of the laboratory. The imputation dummy is significant indicating that the USPTO patents are more inclusive than patents granted in the survey. Despite the larger sample size, significance levels drop, suggesting some mismatching of imputed patents to laboratories. But the pattern of the results is similar to those found in (5.1)-(5.4). NSF IUCRC membership has a larger effect than general IUCRC membership. IUCRC effects decrease and become insignificant once additional laboratory characteristics are introduced. These characteristics are significant in (5.6) and (5.8). In additional results we approach IUCRC linkage using R\&D stocks of specifically cited IUCRCs (see section III). We use an approximation that Griliches (1986) developed to study the premium on basic research. Let the effective $\mathrm{R} \& \mathrm{D}$ of closely affiliated universities $\mathrm{Y}^{*}$ be

\footnotetext{
${ }^{23}$ The data consist of all patents issued to the parent firm by the USPTO. Patents are matched to laboratory locations using the two-digit zipcode for inventors listed on the patents and the laboratories.

${ }^{24}$ The test uses the result that $-2 \log \left(\mathrm{L}_{0} / \mathrm{L}_{1}\right) \sim \chi^{2}(\mathrm{r}-\mathrm{s})$ where $\mathrm{L}_{0}$ is the restricted likelihood, $\mathrm{L}_{1}$ is the unrestricted likelihood, and r-s is the number of additional variables included in the unrestricted likelihood.
} 


$$
Y^{*}=Y+(1+\delta) \bullet X
$$

Part of $\mathrm{Y}^{*}$ consists of the R\&D stock of closely affiliated universities $\mathrm{Y}$ and part consists of the R\&D stock of cited IUCRCs, X, which carries a premium of $\delta$. The following approximation holds, provided that $\mathrm{X}$ is a small fraction of $\mathrm{Y}$ :

$$
\log \left(Y^{*}\right)=\log [Y+(1+\delta) X]=\log \{[1+(1+\delta)(X / Y)] Y\} \approx \delta \bullet X / Y+\log (Y)
$$

To estimate $\delta$ we construct $\mathrm{Y}$ and $\mathrm{X} / \mathrm{Y}$. We construct $\mathrm{Y}$ using federally funded R\&D stocks of universities that are closely affiliated with the laboratories, as in Adams (2000). We obtain X from stocks of IUCRC R\&D from the IUCRC survey. From $\mathrm{X}$ and $\mathrm{Y}$ we construct $\mathrm{X} / \mathrm{Y}$ or IUCRC R\&D/Federal R\&D ${ }^{25}$. Log (Y) is the logarithm of Federal R\&D of closely affiliated universities. But $\delta$ is insignificant and there is no premium, perhaps because of data errors. R\&D in closely affiliated universities is significant in these results.

\section{B. Determinants of Laboratory R\&D}

Table 6 studies determinants of laboratory R\&D. Total R\&D expenditure is the dependent variable in (6.1)-(6.2). A small portion of this research, expenditures on learning about universities, is the dependent variable in (6.3)-(6.4). The specification of the R\&D equation is shown in (4) below.

$\log$ (laboratory R\&D) = g [time, industry, laboratory specialization, $\log$ (recent firm sales), $\log (\mathrm{R} \& \mathrm{D}$ in the rest of the firm), $\log$ (number of Ph.D.s), $\log$ (lagged 20 year stock of the firm's patents near the laboratory), fraction of non-engineering fields important to the laboratory].

All the independent variables of table 5 except for laboratory R\&D are included in table 6 . In addition we include the deflated stock of sales of parent firms over the preceding 12 years,

\footnotetext{
${ }^{25}$ The stock of R\&D in the IUCRCs is about $1 / 2$ of 1 percent of the stock of R\&D in closely affiliated universities so that $\mathrm{X}$ is indeed much less than $\mathrm{Y}$ in this case.
} 
depreciated at $10 \%$ per year. This Compustat variable captures firm size and hence appropriability of the returns to R\&D.

We use ordinary least squares (OLS) in (6.1)-(6.2) but Tobit analysis in (6.3)-(6.4) since R\&D expenditures on universities are positive for just $40 \%$ of the observations, and Tobit analysis allows for censoring of laboratory expenditures on universities at zero ${ }^{26}$.

Firm sales and numbers of Ph.D. (or MD) researchers behave like measures of size and appropriability. Both have positive and significant effects on laboratory R\&D. The stock of firm patents near the laboratory is significant for R\&D because of persistence in individual propensities to patent. The share of non-engineering fields is positively associated with $R \& D$ expenditures, probably because science-intensive laboratories have a larger efficient size. In contrast rest of firm R\&D substitutes for laboratory R\&D, once sales are held constant.

Consider next the IUCRC membership variables. IUCRC effects are positive and significant in (6.1)-(6.2). Again NSF IUCRC membership has the larger effect. The point estimates imply that IUCRCs increase expenditures by 0.4 million on a base of 22.7 million, an increase of $2 \%$. The effect of NSF IUCRCs is estimated to be 1.5 million, an increase of $7 \%$. We are quite skeptical about the size of the NSF effect especially given the matching of NSF centers to larger and more productive laboratories. Turning to laboratory expenditures on universities in (6.3-6.4), IUCRC membership strengthens, suggesting that IUCRCs increase industry support for universities.

One way to interpret these results is that IUCRCs provide new projects and stimulate industrial research. And yet IUCRC laboratories are larger than average (see fn. 22), so another

\footnotetext{
${ }^{26}$ Greene (2000), p. 909 stresses a pitfall in the comparison between OLS and Tobit. OLS coefficients equal their marginal effects but Tobit coefficients exceed their marginal effects. In Tobit marginal effects $\mathrm{M}$ are related to the coefficients $\mathrm{B}$ as $\mathrm{M}=(1-\mathrm{f}) \bullet \mathrm{B}$ where $\mathrm{f}$ is the fraction of observations censored. This is important to remember when comparing 6.1-6.2 (OLS) with 6.3-6.4 (Tobit).
} 
way to interpret the findings is that larger laboratories are attracted to the IUCRCs. This is not necessarily a bad result since it suggests that IUCRCs and especially the NSF IUCRCs attract excellent laboratories to work with them.

\section{Simultaneous Equation Estimates for Patents and IUCRC Membership}

Tables 7 and 8 conclude the empirical work. In these tables we estimate patent and IUCRC membership equations jointly in a two-equation system. Since laboratory size and proficiency determine IUCRC membership as well as patents we treat membership as a dummy endogenous variable in a simultaneous equations system ${ }^{27}$. We break up laboratory patents into increasing brackets ranging from 1 to 10 and estimate equations for patents assigned to the brackets (PATCAT) using Ordered Probit. This makes it possible to estimate the correlation between PATCAT and the Probit indicator for IUCRC using bivariate normal theory ${ }^{28}$. Adams, Chiang and Jensen (2000), section IV, explains this statistical method in more detail.

The specification of the two equations in tables 7 and 8 is shown by (5) below.

Ordered Patents $=\mathrm{f}^{*}$ [time, industry, laboratory specialization, $\log (\mathrm{R} \& \mathrm{D}$ budget $)$, $\log (\mathrm{R} \& \mathrm{D}$ in the rest of the firm), $\log$ (number of Ph.D.s), $\log$ (lagged 20 year stock of the firm's patents near the laboratory), fraction of non-engineering fields important to the laboratory]

IUCRC Membership $=\mathrm{h}$ [time, industry, laboratory specialization, $\log$ (R\&D budget), log ( federally funded R\&D in closely affiliated universities, faculty consulting, joint authorship with faculty, graduate student hiring].

As usual we include industry and time dummies, laboratory specialization dummies, and laboratory R\&D budget in both equations. The variables in the PATCAT equation (with their function in parentheses) are the logarithm of laboratory R\&D budget (laboratory size and

\footnotetext{
${ }^{27}$ Maddala (1983), Chapter 5 is a useful reference. We ignore the specification that uses both non-NSF and NSF IUCRC membership dummies because this would require use of the trivariate normal distribution, and is less tractable for estimation.
} 
proficiency), numbers of Ph.D. scientists (size and focus on applied research), and the 20 year stock of the firm's patents near the laboratory (propensity to patent). Also included are share of non-engineering science fields cited by the laboratory (focus on research, not development), the logarithm of R\&D in the rest of the firm (firm size and within-firm knowledge flows), and the IUCRC membership dummies.

The IUCRC equation includes the logarithm of laboratory R\&D (laboratory size and proficiency) and the logarithm of federally funded R\&D in closely affiliated universities (academic spillovers). IUCRC is also influenced by the importance of university faculty consulting, joint authorship with university scientists and hiring of graduate students, which we regard as predetermined sentiments for university collaboration. The IUCRC equation does not include PATCAT because to do so would violate the condition that the probabilities in the likelihood function sum to 1.0 (Maddala, 1983).

Several variables enter PATCAT but not IUCRC because they affect patents but not the incentives to join IUCRCs. These are numbers of Ph.D. scientists, the stock of the firm's patents close to the laboratory, the share of non-engineering science fields, and rest of firm $R \& \mathrm{D}^{29}$. Similarly, federally funded R\&D in closely affiliated universities and importance of faculty consulting, co-authorship with faculty and hiring graduate students attract laboratories to IUCRCs but have weak effects on patents. These assumptions identify the equation system. Table 7 reports the findings using patents granted. Single equation estimates for PATCAT and IUCRC comprise (7.1) and (7.2). The results for PATCAT are similar to table 5 except that the coefficient on R\&D budget declines and that of IUCRC increases. These changes

\footnotetext{
${ }^{28}$ One disadvantage of transforming patents into an Ordered Probit indicator is that the right tail of patents is truncated by classification into the highest bracket. Little can be done about this given sample size limits for each of the cells.

${ }^{29}$ Consistent with this view all these variables are individually and jointly insignificant in the IUCRC equation.
} 
are an artifact of top coding — of grouping large laboratories' patents into the top bracket. There is little that can be done about this given the goal of estimating the correlation between the two equations.

Turning to (7.2) laboratory budget increases the probability of joining an IUCRC. This is consistent with the size advantage of joining IUCRCs. Also the stock of R\&D in closely affiliated universities increases the chance of membership, very likely because IUCRCs are more common in larger universities. Finally the importance of faculty consulting and of co-authorship with university faculty are the dominant preferences that influence membership. Importance of hiring graduate students is insignificant in the IUCRC equation. These findings suggest that IUCRCs are primarily a vehicle for faculty consulting and research. In this way the regressionstyle findings of table 7 select among the descriptive choices of table 3 .

The simultaneous equation results appear in (7.3) and (7.4) and are close to the single equation results except that the coefficient of laboratory R\&D declines in PATCAT while the IUCRC coefficient increases sharply. Standard errors also increase. All these changes are the result of estimating the cross-equation correlation coefficient which is $\rho=-0.46(t=-1.5)$ and not estimated with much precision. The important point is that the simultaneous equation analysis does not change the findings, even though top coding of the patent variable artificially increases the significance of IUCRC for patents.

Table 8 carries out a simultaneous equation analysis for hybrid patents whose bracketed form we label as HPATCAT. As in table 5 IUCRC and most of the other variables enter weakly compared with the results for patents granted. As in table 7 taking simultaneity into account does not change these results very much. In the single equation HPATCAT results membership in IUCRCs has a coefficient of $0.30(\mathrm{t}=2.1)$, larger than in table 5 because of the top coding of 
patents required by our technique. In the simultaneous equation results IUCRC has a coefficient of 0.77 but the t-statistic declines to 1.4 because standard errors increase. The cross-equation correlation is $\rho=-0.31(\mathrm{t}=-0.9)$ but again this is not estimated with much precision.

In summary, the simultaneous equation analysis of patents and IUCRC membership, where the latter is an endogenous variable, does not produce major changes in our findings. IUCRC is more significant in tables 7 and 8 than in table 5. But this is a by-product of the Ordered Probit transformation, necessary if we are to use bivariate normal theory in estimation. The influence of IUCRC membership on patents remains small once laboratory size and proficiency are taken into consideration.

\section{Conclusion}

This paper has presented evidence on the influence that Industry University Cooperative Research Centers have on industrial R\&D laboratories. Rather than repeat the discussion, we think it more useful to consider the problem of identifying the influence of the IUCRCs on industrial laboratories in greater depth, and to consider other aspects of the IUCRCs.

We have given reasons for thinking that laboratory size and excellence are part of what drives the appearance of positive IUCRC effects on patents and research expenditure. The next research problem suggested by this is to further identify the IUCRC effect. This is mostly a data issue and could be profitably addressed by having more and better evidence that would allow us to control for "fixed effects" of the laboratories, which are the composite of their unmeasured characteristics. To break this deadlock, one would need panel data that includes more laboratories over a longer period and a lengthy time series of membership indicators, including the dates when laboratories join and resign from IUCRCs, along with size, quality, R\&D, and 
other characteristics of the IUCRCs. Such data do not yet exist but they are likely to be helpful in separating the effect that IUCRCs have on R\&D laboratories from the effect that laboratory characteristics have on the decision to join IUCRCs. These improved data allow this by permitting differencing of the data on member firms, as a result removing the influence of fixed effects. Even better would be a situation where differences in patenting and research expenditures of member laboratories are treated as net of corresponding differences in nonmember laboratories for the same time period. This "difference in differences" analysis (Klette, Moen and Griliches, 2000) would allow a better accounting for time effects.

There are many other aspects of IUCRCs that we have barely touched. We noted that IUCRCs benefit faculty, but the salary effects are unknown. One would also like to know whether IUCRCs benefit the rest of the university, in particular whether the "input expansion" effects of IUCRCs on universities dominate "input diversion." Under input expansion more faculty are added and on-campus faculty time does not decrease. Under input diversion the same number of faculty reduce their on-campus time by spending it on company-related research. Another decision concerns whether to finance the IUCRCs using federal grants versus industry support. More grants would build up the centers at the possible expense of interaction with firms. Finally, we have ignored cost-benefit aspects of IUCRCs. On the surface IUCRCs seem to generate more benefits than costs since firms largely support them. Add to this the possibility of knowledge spillovers and the cost-benefit outlook seems favorable indeed. And yet there are costs of obtaining the centers and under free entry into the competition to win IUCRCs, the private rate of return on these centers should equal the normal return, ignoring knowledge spillovers and producers' surplus from IUCRCs. There is much that one can learn, even about supposedly simple institutions like the Industry-University Cooperative Research Centers. 


\section{Table 1}

Distribution of Firms and R\&D Laboratories

by Industry Group of the Parent Firm

\begin{tabular}{lccc}
\hline \hline \multicolumn{1}{c}{ Industry Group } & SIC Code & Number of Firms & Number of R\&D Laboratories $^{*}$ \\
\hline \hline Chemicals & 28 & 32 & 59 \\
Machinery & 35 & 37 & 58 \\
Electrical Equipment & 36 & 33 & 57 \\
Transportation Equipment & 37 & 14 & 34 \\
All Industries & & $\mathbf{1 1 6}$ & $\mathbf{2 0 8}$ \\
\hline
\end{tabular}

Source: Survey of Industrial Laboratory Technologies 1996. " The 208 observations represent 220 laboratories or research groups owing to the grouping of laboratories by several firms.

Table 2

Means of Inputs and Outputs of R\&D Laboratories

Classified by IUCRC Membership

(Standard Deviations in Parentheses)

\begin{tabular}{|c|c|c|}
\hline \multirow[b]{2}{*}{ Variable } & \multicolumn{2}{|c|}{ Industrial R\&D Laboratories } \\
\hline & $\begin{array}{l}\text { Member of } \\
\text { IUCRC }\end{array}$ & $\begin{array}{c}\text { Not a member of } \\
\text { an IUCRC }\end{array}$ \\
\hline \multicolumn{3}{|l|}{ R\&D Inputs } \\
\hline Number of Scientists and Engineers & $\begin{array}{c}256.6 \\
(584.3)\end{array}$ & $\begin{array}{c}92.9 \\
(303.9)\end{array}$ \\
\hline Number of Ph.D. (or MD) Scientists and Engineers & $\begin{array}{c}42.5 \\
(168.6)\end{array}$ & $\begin{array}{c}10.2 \\
(50.7)\end{array}$ \\
\hline Laboratory R\&D Budget (in millions of '87 \$) & $\begin{array}{c}22.7 \\
(55.0)\end{array}$ & $\begin{array}{c}8.4 \\
(29.0)\end{array}$ \\
\hline \multicolumn{3}{|l|}{ R\&D Outputs } \\
\hline Patents Granted from the Survey & $\begin{array}{c}11.5 \\
(17.0)\end{array}$ & $\begin{array}{c}6.3 \\
(26.4)\end{array}$ \\
\hline Hybrid Patents ${ }^{\text {a }}$ & $\begin{array}{l}16.2 \\
(37.5)\end{array}$ & $\begin{array}{l}10.2 \\
(41.8)\end{array}$ \\
\hline $\begin{array}{l}\text { Sales from New Products Originating in the } \\
\text { Laboratory (in millions of ' } 87 \$ \text { ) }\end{array}$ & $\begin{array}{c}285.4 \\
(956.1)\end{array}$ & $\begin{array}{c}30.3 \\
(73.3)\end{array}$ \\
\hline Number of Observations & 122 & 178 \\
\hline
\end{tabular}

Source: Survey of Industrial Laboratory Technologies 1996. The number of observations is $\mathrm{N}=310$. The data are treated as a panel and pooled across years 1991 and $1996 .{ }^{a}$ Hybrid patents are patents granted from the survey with missing patents imputed from USPTO patents by firm and laboratory locations. Means are significantly different at the one-percent level for member and non-member laboratories, except for patents granted and hybrid patents. 
Table 3

$\chi^{2}$ Statistics Testing for Independence of Channels Of University Influence from IUCRC Membership

\begin{tabular}{lc}
\hline \hline \multicolumn{1}{c}{ Channel of University Influence } & \\
\hline \hline Engineering Graduates & $\chi^{2}$ Statistic \\
Science Graduates & $9.5^{*}$ \\
Personnel Movements from University to Lab & $8.7^{*}$ \\
University Faculty Consulting & 4.7 \\
Contract Research & $14.9^{*}$ \\
Flows of University Research Ideas to Industry & $8.9^{*}$ \\
Joint Authorship with University Scientists & 4.0 \\
Licensing of University Patents & $13.5^{*}$ \\
\hline \hline
\end{tabular}

Source: Survey of Industrial Laboratory Technologies 1996. The $\chi^{2}$ statistics test for independence of IUCRC membership from the rated importance of each channel of university influence, where importance is defined as a score of 3 or better on a 5 point Likert scale, and membership in IUCRCs. An * means that the $\chi^{2}$ statistic is significant at greater than the $1 \%$ level, so that the channel and IUCRC membership are unlikely to be independent.

Table 4

Laboratory Membership in IUCRCs and Number of Cited IUCRCs

\begin{tabular}{ccc}
\hline \hline $\begin{array}{c}\text { Number of Cited } \\
\text { IUCRCs }\end{array}$ & $\begin{array}{c}\text { Laboratory is not a Member } \\
\text { of an IUCRC }\end{array}$ & $\begin{array}{c}\text { Laboratory is a Member of an } \\
\text { IUCRC }\end{array}$ \\
\hline 0 & 121 & 42 \\
1 & 5 & 20 \\
2 & 0 & 9 \\
3 & 0 & 2 \\
4 & 0 & 1 \\
Total Number of Laboratories* & 126 & 74 \\
\hline \hline
\end{tabular}

Source: Survey of Industrial Laboratory Technologies 1996 and Survey of Industry-University Cooperative Research Centers 1998. * Eight of the 208 laboratories did not report membership in any type of IUCRC. 
Table 5

Determinants of the Propensity to Patent by R\&D Laboratories

(Asymptotic Normal Statistics in Parentheses)

Variable or Statistic

Patents Granted $^{\text {a }}$

"Hybrid" Patents a, b

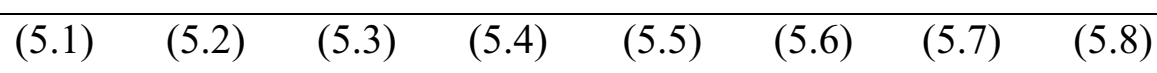

Patents Imputed ( 1 if yes, 0 if no)

$\begin{array}{lll}0.75 & 0.68 \quad 1.00\end{array}$

0.81

(2.8) (2.4) (3.4)

(2.6)

Log (Laboratory R\&D Budget)

$\begin{array}{cc}0.65 & 0.54 \\ (12.1) & (10.0) \\ & 0.10 \\ & (4.3) \\ & 0.05 \\ & (2.3) \\ & -1.28 \\ & (-3.4) \\ 0.05 & 0.04 \\ (3.0) & (2.1) \\ 0.43 & 0.28 \\ (2.5) & (1.7)\end{array}$

0.62

$0.51 \quad 0.57$

0.49

Log (Number of Ph.D. or MD S\&Es in the

(10.0) (8.8)

$(11.9)$

(9.4)

$(10.1)$

$(8.4)$

Laboratory)

(4.3)

(3.4)

0.09

0.08

Log (20 Year Stock of the Firm's Patents

Close to the Laboratory)

0.05

0.03

(3.7)

(2.9)

0.08

0.06

Share of Laboratory S\&E Fields in Science

(2.3)

(1.6)

(3.6)

(2.6)

$-0.72$

$-0.29$

$(-1.8)$

$(-0.6)$

$\log$ (R\&D in the Rest of the Firm)

$(-2.0)$

0.03

0.03

Membership in all IUCRCs

0.43

0.04

0.03

0.06

(1.9)

0.05

(1.4)

(1 if yes, 0 if no)

Membership in NSF IUCRCs

(1 if yes, 0 if no)

(2.1)

(3.3)

(2.5)

$0.29 \quad 0.10$

(1.5) (0.6)

Membership in Non-NSF IUCRCs (1 if yes,

0 if no)

Number of Observations

Log Likelihood

$\begin{array}{cccccccc} & & 0.71 & 0.51 & & & 0.63 & 0.45 \\ & & (2.6) & (1.9) & & & (2.1) & (1.6) \\ & & 0.15 & 0.08 & & & 0.06 & -0.05 \\ 252 & 252 & 235 & 235 & 280 & 280 & 258 & 258 \\ -571.7 & -557.9 & -508.5 & -501.1 & -676.9 & -663.5 & -594.1 & -585.7\end{array}$

Source: Survey of Industrial Laboratory Technologies 1996 and Survey of Industry-University

Cooperative Research Centers 1998. Note: year, industry, testing, and jointly housed dummies are included in all regressions. ${ }^{a}$ The estimation method is negative binomial regression, a type of random effect Poisson regression. " missing values are imputed by U.S. Patent Office patents for the firm and two-digit zipcode of the laboratory. 


\section{Table 6}

Determinants of R\&D Expenditures by R\&D Laboratories (Asymptotic Normal Statistics in Parentheses)

\begin{tabular}{|c|c|c|c|c|}
\hline \multirow[t]{2}{*}{ Variable or Statistic } & \multicolumn{2}{|c|}{$\begin{array}{c}\log (\mathrm{R} \& \mathrm{D} \\
\text { Expenditure })^{\text {a }}\end{array}$} & \multicolumn{2}{|c|}{$\begin{array}{c}\log (\mathrm{R} \& \mathrm{D} \\
\text { Expenditure on } \\
\text { Universities) }^{\mathrm{b}}\end{array}$} \\
\hline & $(6.1)$ & $(6.2)$ & $(6.3)$ & $(6.4)$ \\
\hline Log (Recent Sales of the Firm) & $\begin{array}{l}0.32 \\
(7.0)\end{array}$ & $\begin{array}{l}0.31 \\
(6.6)\end{array}$ & $\begin{array}{l}0.39 \\
(2.6)\end{array}$ & $\begin{array}{l}0.32 \\
(2.2)\end{array}$ \\
\hline Log (Number of Ph.D. or MD S\&Es in the & 0.14 & 0.12 & 0.53 & 0.46 \\
\hline Laboratory) & $(6.9)$ & $(5.5)$ & $(7.1)$ & $(6.0)$ \\
\hline $\begin{array}{l}\text { Log ( } 20 \text { Year Stock of the Firm's Patents Close } \\
\text { to the Laboratory) }\end{array}$ & $\begin{array}{l}0.06 \\
(3.1)\end{array}$ & $\begin{array}{l}0.05 \\
(2.6)\end{array}$ & $\begin{array}{l}0.03 \\
(0.5)\end{array}$ & $\begin{array}{l}-0.02 \\
(-0.3)\end{array}$ \\
\hline $\begin{array}{l}\text { Share of Laboratory S\&E Fields in Science } \\
\text { rather than Engineering }\end{array}$ & $\begin{array}{l}1.02 \\
(2.9)\end{array}$ & $\begin{array}{l}1.39 \\
(3.8)\end{array}$ & $\begin{array}{l}4.95 \\
(4.0)\end{array}$ & $\begin{array}{l}5.27 \\
(4.1)\end{array}$ \\
\hline $\log (\mathrm{R} \& \mathrm{D}$ in the Rest of the Firm) & $\begin{array}{l}-0.09 \\
(-4.4)\end{array}$ & $\begin{array}{l}-0.10 \\
(-4.8)\end{array}$ & $\begin{array}{l}-0.01 \\
(-0.2)\end{array}$ & $\begin{array}{l}-0.02 \\
(-0.3)\end{array}$ \\
\hline $\begin{array}{l}\text { Membership in all IUCRCs } \\
(1 \text { if yes, } 0 \text { if no) }\end{array}$ & $\begin{array}{l}0.32 \\
(2.0)\end{array}$ & & $\begin{array}{l}1.75 \\
(3.5)\end{array}$ & \\
\hline $\begin{array}{l}\text { Membership in NSF IUCRCs } \\
\text { ( } 1 \text { if yes, } 0 \text { if no) }\end{array}$ & & $\begin{array}{l}0.91 \\
(3.6)\end{array}$ & & $\begin{array}{l}3.66 \\
(5.1)\end{array}$ \\
\hline $\begin{array}{l}\text { Membership in Non-NSF IUCRCs } \\
\text { (1 if yes, } 0 \text { if no) }\end{array}$ & & $\begin{array}{l}0.01 \\
(0.0)\end{array}$ & & $\begin{array}{l}0.54 \\
(1.0)\end{array}$ \\
\hline Number of Observations & 280 & 258 & 274 & 252 \\
\hline Fraction of Observations Left Censored at Zero & -- & -- & 0.58 & 0.60 \\
\hline Root Mean Squared Error & 1.18 & 1.16 & 3.14 & 3.01 \\
\hline Adjusted $\mathrm{R}^{2}$ & 0.53 & 0.52 & -- & -- \\
\hline Log Likelihood & -- & -- & -370.0 & -325.9 \\
\hline
\end{tabular}

Source: Survey of Industrial Laboratory Technologies 1996 and Survey of Industry-University Cooperative Research Centers 1998. Note: year, industry, testing, and jointly housed dummies are included in all regressions. ${ }^{a}$ Estimation method is ordinary least squares or OLS regression. ${ }^{\mathrm{b}}$ Estimation method is Tobit Analysis. 
Table 7

Joint Estimation of the Propensity to Patent and to Join IUCRCs

By R\&D Laboratories, Patents Granted

(Asymptotic t-Statistics in Parentheses)

Variable or Statistic

PATCAT $^{\mathrm{a}}$ IUCRC $^{\mathrm{b}}$ PATCAT $^{\mathrm{c}}$ IUCRC $^{\mathrm{c}}$

$\begin{array}{llll}(7.1) & (7.2) \quad(7.3) \quad(7.4)\end{array}$

Log (Laboratory R\&D Budget)

Log (Number of Ph.D. or MD S\&Es in the Laboratory)

Log (20 Year Stock of the Firm's Patents Close to the Laboratory)

Share of Laboratory S\&E Fields in Science rather than

Engineering

$\log (\mathrm{R} \& \mathrm{D}$ in the Rest of the Firm)

IUCRC ( 1 if yes, 0 if no)

Log (Federally Funded R\&D In Closely Affiliated Universities, Net of IUCRCs)

Importance of University Faculty Consulting ( 1 if yes, 0 if no)

Importance of Joint Authorship with University Scientists (1 if yes, 0 if no)

Importance of Hiring Graduate Students ( 1 if yes, 0 if no)

Log Likelihood

Cross-Equation Correlation

$\begin{array}{ccc}0.53 & 0.18 & 0.45 \\ (8.6) & (2.8) & (4.8) \\ 0.08 & & 0.07 \\ (3.7) & & (2.8) \\ 0.04 & & 0.04 \\ (1.9) & & (2.1) \\ -0.81 & & -0.86 \\ (-2.3) & & (-2.6) \\ 0.04 & & 0.03 \\ (2.5) & & (2.0) \\ 0.48 & & 1.15 \\ (3.1) & & (2.5)\end{array}$

0.18

0.05

$(2.8)$

0.65

(2.7)

0.48

(2.2)

$-0.37$

$(-1.2)$

$-417.7 \quad-134.5$

$-551.3$

$-0.46$

$(-1.5)$

Sources: Survey of Industrial Laboratory Technologies 1996 and Survey of Government Laboratory R\&D 1998. The number of observations is $\mathrm{N}=252$. Note: year, industry, testing, and jointly housed dummies are included in all regressions. ${ }^{a}$ Estimation method is ordered probit analysis. ${ }^{\mathrm{b}}$ Estimation method is Probit Analysis. ${ }^{\mathrm{c}}$ Estimation method is two equation maximum likelihood. 
Table 8

Joint Estimation of the Propensity to Patent and to Join IUCRCs

By R\&D Laboratories, "Hybrid" Patents "

(Asymptotic t-Statistics in Parentheses)

Variable or Statistic

HPATCAT $^{\mathrm{b}}$ IUCRC $^{\mathrm{c}}$ HPATCAT $^{\mathrm{d}}$ IUCRC $^{\mathrm{d}}$

$(8.1)$

$(8.2)$

$(8.3)$

$(8.4)$

Log (Laboratory R\&D Budget)

Log (Number of Ph.D. or MD S\&Es in the Laboratory)

Log (20 Year Stock of the Firm's Patents Close to the Laboratory)

Share of Laboratory S\&E Fields in Science rather than

Engineering

$\log (\mathrm{R} \& \mathrm{D}$ in the Rest of the Firm)

IUCRC ( 1 if yes, 0 if no)

Log (Federally Funded R\&D In Closely Affiliated

Universities, Net of IUCRCs)

Importance of University Faculty Consulting ( 1 if yes, 0 if

no)

Importance of Joint Authorship with University Scientists

( 1 if yes, 0 if no)

Importance of Hiring Graduate Students ( 1 if yes, 0 if no)

Log Likelihood

Cross-Equation Correlation
0.43

(7.8)

0.07

$(3.2)$

0.07

(3.8)

$-0.65$

$(-2.0)$

0.03

(1.9)

0.30

(2.1)

0.16

(2.7)

0.39

(4.9)

0.06

(2.5)

0.07

(3.9)

$-0.68$

0.03

(1.6)

0.77

(1.4)

0.05

(3.2)

0.64

(2.7)

0.47

(2.3)

$-0.21$

$(-0.7)$

$-476.1$

$-149.4$
0.15

0.04

(2.5)

0.64

(2.8)

0.52

(2.6)

$-0.21$

$(-0.7)$

Sources: Survey of Industrial Laboratory Technologies 1996 and Survey of Government

Laboratory R\&D 1998. The number of observations is $\mathrm{N}=280$. Note: year, industry, testing, and jointly housed dummies are included in all regressions. " "Hybrid" patents are patents granted in the survey where missing values are imputed by U.S. Patent Office patents for the firm and two-digit zipcode of the laboratory. ${ }^{\mathrm{b}}$ Estimation method is ordered probit analysis.

${ }^{c}$ Estimation method is Probit Analysis. ${ }^{d}$ Estimation method is two equation maximum likelihood. 


\section{References}

Adams, James D., Survey of Industrial Laboratory Technologies 1996, processed, Department of Economics, University of Florida, 1997. , Survey of Industry-University Cooperative Research Centers

1998, processed, Department of Economics, University of Florida, 1998. , "Endogenous R\&D Spillovers and Industrial Research Productivity,"

NBER Working Paper \#7484, January 2000.

Adams, James D., Eric P. Chiang and Jeffrey L. Jensen, “The Influence of Federal Laboratory R\&D on Industrial Research,” NBER Working Paper \#7612, March 2000.

Blumenthal, David, Michael Gluck, Karen Seashore Louis, and David Wise, "Industrial Support of University Research in Biotechnology,” Science 231 (17 January 1986): 242-246.

Brooks, Harvey, and Lucien P. Randazzese, "University-Industry Relations: The Next Four Years and Beyond," in Lewis M. Branscomb and James H. Keller, Investing in Innovation: Creating a Research and Innovation Policy that Works, Cambridge, Massachusetts: MIT Press, 1998.

Brownlee, K.A., Statistical Theory and Methodology in Science and Engineering, $2^{\text {nd }}$ edition, John Wiley and Sons, New York, 1967.

Cohen, Wesley M., Richard Florida, Lucien P. Randazzese and John Walsh, "Industry and the Academy: Uneasy Partners in the Cause of Technological Advance," in Roger Noll, ed., Challenges to Research Universities, Washington, D.C., Brookings Institution Press, 1998. 
Gray, Denis O., "National Science Foundation Industry-University Cooperative

Research Centers, Final Structural Information," processed, North Carolina State University, various years.

Greene, William H., Econometric Analysis, $4^{\text {th }}$ ed., Upper Saddle River, New Jersey, PrenticeHall, 2000.

Griliches, Zvi, "Productivity, R\&D, and Basic Research at the Firm Level During the 1970s," American Economic Review 76 (March 1986): 141-154.

Hausman, Jerry, Bronwyn Hall, and Zvi Griliches, "Economic Models for Count Data, with an Application to the Patents-R\&D Relationship,” Econometrica 52 (July 1984): 909-938.

Henderson, Rebecca, Adam B. Jaffe, and Manuel Trajtenberg, "Universities as a Source of Commercial Technology: A Detailed Analysis of University Patenting: 1965-1988," The Review of Economics and Statistics (February 1998): 119-127.

Klette, Tor Jacob, Jarle Moen, and Zvi Griliches, "Do Subsidies to Commercial R\&D Reduce Market Failures? Microeconometric Evaluation Studies,” Research Policy 29 (2000): 471-495.

Link, Albert N., and Laura L. Bauer, Cooperative Research in U.S. Manufacturing: Assessing Policy Initiatives and Corporate Strategy, Lexington, Massachusetts, Heath, 1989.

Maddala, G.S., Limited-Dependent and Qualitative Variables in Econometrics, Cambridge, UK: Cambridge University Press, 1983.

Mowery, David C., "The Boundaries of the U.S. Firm in R\&D," in N. R. Lamoureaux and D. M. G. Raff, editors, Coordination and Information: Historical Perspectives on the Organization of Enterprise, Chicago, University of Chicago Press for NBER, 1995. 
National Science Board, Science and Engineering Indicators 1998, Washington D.C., National Science Foundation, 1998.

Thursby, Jerry G., and Marie C. Thursby, "Who is Selling the Ivory Tower? Sources of Growth in University Licensing," NBER Working Paper \#7718, May 2000. 